\title{
Pengaruh Kecemasan Dan Sikap Siswa Pada Pembelajaran Matematika Terhadap Hasil Belajar Aritmatika Sosial Siswa Kelas VII SMP Di Kecamatan Burau
}

\author{
Subaedah ${ }^{1}$, Muhammad Ilyas ${ }^{2}$, Nurdin $^{3}$ \\ SMP Negeri 2 Burau ${ }^{1,}$ Universitas Cokroaminoto Palopo ${ }^{2}$ \\ Universitas Muhammadiyah Enrekang ${ }^{3}$ \\ Email: subaedahsaleh1@gmail.com¹,muhammadilyas949@yahoo.com², \\ enambelasnurdin@gmail.com ${ }^{3}$
}

\begin{abstract}
Abstrak. Penelitian ini merupakan penelitian ex post facto dengan sampel 85 orang siswa kelas VII SMP di Kecamatan Burau yang diambil secara random sampling. Variabel penelitian terdiri dari kecemasan dan sikap siswa pada pembelajaran matematika sebagai variabel bebas dan hasil belajar Aritmatika Sosial sebagai variabel terikat. Instrumen penelitian menggunakan angket kecemasan matematika, angket sikap siswa pada pembelajaran matematika, dan tes hasil belajar aritmatika sosial. Analisis data menggunakan analisis regresi linier sederhana untuk mengetahui pengaruh variable bebas secara parsial dan analisis regresi linier berganda untuk mengetahui pengaruh secara simultan. Hasil penelitian menunjukkan bahwa terdapat pengaruh kecemasan matematika terhadap hasil belajar siswa kelas VII SMP di kecamatan Burau sebesar 8,9\%. Terdapat pengaruh sikap siswa pada pembelajaran matematika terhadap hasil belajar siswa kelas VII SMP di kecamatan Burau sebesar 19,4\%. Terdapat pengaruh secara bersama-sama kecemasan dan sikap pada pembelajaran matematika siswa kelas VII SMP di Kecamatan Burau sebesar 21,8\%. Dengan demikian dapat disimpulkan jika tingkat kecemasan matematika siswa rendah dan sikap siswa pada pembelajaran matematika berada pada kategori baik, maka hasil belajar aritmatika sosial siswa tinggi. Sebaliknya, jika tingkat kecemasan matematika siswa tinggi dan sikap siswa pada pembelajaran matematika kurang baik, maka hasil belajar aritmatika sosial siswa akan rendah.
\end{abstract}

\section{Kata Kunci: Kecemasan, Sikap Siswa Pada Pembelajaran Matematika, Hasil Belajar}

\begin{abstract}
This research is an ex post facto research with a sample of 85 students of class VII SMP in Burau District taken by random sampling. The research variables consisted of students' anxiety and attitudes towards mathematics learning as independent variables and Social Arithmetic learning outcomes as the dependent variable. The research instrument used a mathematical anxiety questionnaire, a student attitude questionnaire in learning mathematics, and a social arithmetic learning outcome test. Data analysis used simple linear regression analysis to determine the independent variables partially and multiple linear regression analysis to determine the effect simultaneously. The results showed that there was an influence of mathematics anxiety on the learning outcomes of seventh grade junior high school students in Burau sub-district of $8.9 \%$. There is an influence of students' attitudes in learning mathematics on the learning outcomes of class VII junior high school students in Burau sub-district by $19.4 \%$. There is a joint influence of anxiety and attitudes on mathematics learning for seventh grade junior high school students in Burau District by $21.8 \%$. Thus, it can be concluded that if students' mathematics anxiety level is low and students' attitudes towards mathematics learning are good, then students' social arithmetic learning outcomes will be high. On the other hand, if the students' mathematics anxiety level is high and students' attitudes towards mathematics learning are not good, then the students' social arithmetic learning outcomes will be low.
\end{abstract}

Keywords: Anxienty, Student Response on Laerning Mathematics, Learning Achievement

\section{A. Pendahuluan}

Matematika adalah ilmu universal yang menjadi dasar perkembangan teknologi, memiliki peranan penting dalam disiplin ilmu yang lainnya dan dan dapat membantu dalam menyelesaikan berbagai permasalahan dalam kehidupan. Tujuan diajarkannya matematika adalah meningkatkan kecerdasan, pengetahuan, karakkter, kepribadian, akhlak mulia, dan serta 
keterampilan untuk hidup mandiri untuk menjadi bekal dalam kehidupan nyata. Hal tersebut menunjukan, bahwa pentingnya menguasai matematika sedini mungkin.

Namun kenyataannya, matematika masih dianggap momok bagi siswa. ini terlihat dari hasil capaian penilaian Programme for International Student Assessment (PISA) 2018 skor ratarata kemampuan matematika siswa indonesia sebesar 379 berada pada peringkat 67 dari 73 negara peserta (OECD, 2019). Rendahnya hasil belajar ini di karenakan pembelajaran matematika dianggap sulit dan menakutkan oleh siswa. Angggapan bahwa pelajaran matematika sulit dan menakutkan bagi siswa akan menimbulkan kecemasan ketika belajar matematika, serta akan membuat siswa memiliki sikap malas, dan jenuh ketika belajar matematika sehingga dapat mempengaruhi hasil belajarnya.

Kecemasan dapat memengaruhi hasil belajar matematika siswa karena dengan kecemasan berlebih cenderung membuat siswa kurang termotivasi dalam pembelajaran. Kecemasan bisa berdampak baik dan buruk. Kecemasan berdampak baik apabila masih tergolong wajar dan terkendali, karena kinerja fisik dan intelektual siswa didorong dan diperkuat oleh kecemasan. Kecemasan seperti ini akan mendorong siswa lebih mempersiapkan diri untuk proses pembelajaran matematika. Sebaliknya, kecemasan memberikan dampak buruk terjadi ketika tingkat kecemasan berlebihan dan tidak terkendali. Kecemasan seperti ini membuat siswa sulit berkonsentrasi. Siswa dengan tingkat kecemasan yang berlebihan cenderung bersikap pesimis dalam menyelesaikan masalah matematika dan kurang termotivasi untuk mempelajarinya. Kecemasan yang berlebihan juga seringkali memposisikan matematika menjadi mata pelajaran yang ditakuti dan dihindari (Astuti, 2016). Berdasarkan hal tersebut. Pada pembelajaran matematika kecemasan perlu diperhatikan, apabila kecemasan muncul dalam diri siswa dan tidak segera dikenali oleh siswa maupun guru maka kecemasan bisa mengarah pada hal-hal yang negatif.

Hasil penelitian Ikhsan (2019) menyimpulkan bahwa kecemasan matematika berpengaruh negatif terhadap hasil belajar matematika siswa. Hal yang sama dikemukakan Disai, Dariyo, \& Basaria, (2018) terdapat hubungan signifikan negatif antara kecemasan Matematika dan hasil belajar Matematika siswa SMA. Artinya jika kecemasan tinggi maka hasil belajar rendah begitu sebaliknya. Selain kecemasan matematika, sikap siswa pada pembelajaran juga memengaruhi hasil belajar matematika siswa. hal ini dikarenakan pembelajaran di sekolah saat ini menekankan pada peningkatan kemampuan dan keterampilan siswa,juga menekankan pada sikap dan karakter siswa.

Sikap merupakan kecenderungan pola tingkah laku individu untuk berbuat sesuatu dengan cara tertentu terhadap orang, benda atau gagasan (Purnomo, 2016) Sikap siswa dan pada pembelajaran merupakan salah satu faktor penentu berhasil atau tidak pembelajaran, utamanya pembelajaran matematika. Jika siswa mempunyai sikap positif terhadap pelajaran matematika maka dia akanmengkategorikan matematikasebagai pelajaran yang menarik serta bermanfaat untuk di pelajari. Sebaliknya, jika siswamereaksi negatif terhadap pelajaran matematika maka dia akan mengkategorikanpelajaran matematika sebagai pelajaran yang tidak menarik dan kurang bermanfaat untuk di pelajari (Hartati, 2015). Hal tersebut akan membuat siswa merasa malas dan jenuh dalam pembelajaran matematika sehngga berdampak pada hasil belajarnya.

Hasil penelitian Susilo \& Agustin (2015) menyimpulkan ada pengaruh positif dan signifikan antara sikap siswa pada matematika terhadap hasil belajar matematika. lebih lanjut, hasil penelitian Karim (2015) menyimpulkan pengaruh signifikan antara sikap siswa pada pembelajaran dan kemampuan berpikir kritis siswa. Siswa yang memiliki sikap positif pada pelajaran matematika memiliki kemampuan berpikir kritis lebih tinggi daripada siswa yangmemiliki sikap negatif pada pelajaran matematika.

Berdasarkan uraian diatas, peneliti tertarik mengkaji Pengaruh Kecemasan Matematika dan Sikap Siswa pada Pembelajaran Matematika terhadap Hasil Belajar Aritmatika Sosial Siswa Kelas VII SMP Di Kecamatan Burau. 


\section{B. Metodologi Penelitian}

Penelitian ini adalah penelitian ex post facto yang bertujuan untuk mengkaji pengaruh kecemasan dan sikap siswa pada pembelajaran matematika terhadap hasil belajar siswa kelas VII SMP di Kecamatan Burau. Penelitian ini dilaksanakan di sekolah menengah pertama (SMP) yang ada di kecamatan Burau Kabupaten Luwu Timur. Waktu penelitan ini di laksanakan di semester genap tahun ajaran 2020/2021.

Populasi dalam penelitian ini yaitu siswa kelas VII SMP di kecamatan Burau yang terdiri 3 sekolah yaitu: 1) SMP Negeri 1 Burau sebanyak 147 siswa, 2) SMP Negeri 2 Burau sebanyak 130 siswa, dan 3) SMP Negeri 3 Burau sebanyak 130 siswa. Sampel penelitian ini sebanyak 85 siswa. Teknik pemilihan sampel yang digunakan yaitu teknik simple random sampling, yaitu mengambil sampel secara acak. Data dalam penelitian ini diperoleh dari hasil tes dan dan non tes (angket) siswa. Instrumen yang digunakan dalam penelitian ini yaitu angket kecemasan matematika, angket sikap siswa pada pembelajaran matematika dan tes hasil belajar aritmatika sosial.

Data yang diperoleh dalam penelitian ini dianalisis secara statistika deskriptif untuk melihat gambaran setiap variable dan statistic inferensial untuk menguji hipotesis, Uji hipotesis yang digunakan adalah regresi linier sederhana (uji hipotesis 1 dan 2) dan regresi linier berganda (uji hipotesis 3) dengan uji prasyarat yaitu uji normalitas, uji linieritas dan uji heterokedastisitas.

\section{Hasil Penelitian dan Pembahasan}

\section{Kecemasan Matematika Siswa}

Berdasarkan hasil analisis yang dilakukan, diperoleh gambaran kecemasan siswa kelas VII SMP di Kecamatan Burau sebagai berikut.

Tabel 1. Hasil uji deskripsi Kecemasan Matematika siswa kelas VII SMP di kecamatan Burau

\begin{tabular}{lc}
\hline & \multicolumn{1}{c}{ Statistics } \\
\hline Jumlah sampel & Kecemasan Matematika \\
Rata-rata & 85 \\
Median & 111,46 \\
Standar deviasi & 112,00 \\
Variansi & 15,51 \\
Rentang & 240,54 \\
Nilai terendah & 72,00 \\
Nilai tertinggi & 76,00 \\
\hline
\end{tabular}

Sumber: Hasil Analisis Data Primer SPSS (2021)

Sumber: Hasil output SPSS (2021)

Berdasarkan Tabel 1, terlihat bahwa dari 85 siswa, rata-rata skor kecemasan matematika siswa kelas VII SMP di kecamatan Burau sebesar 111,46, dengan median sebesar 112,00, nilai tertinggi sebesar 162,00, dan nilai terendah sebesar 94,00.

Data kecemasan matematika siswa kelas VII SMP di kecamatan Burau, selanjutnya dikategorisasi menjadi lima kelompok. Maka diperoleh distribusi frekuensi kecemasan matematika siswa kelas VII SMP di kecamatan Burau sebagai berikut. 
Tabel 2. Distribusi frekuensi kecemasan matematika siswa kelas VII SMP di kecamatan Burau

\begin{tabular}{lllc}
\hline \multicolumn{1}{c}{ Interval } & Frekuensi & Persentae & Kategori \\
& \multicolumn{1}{c}{ (\%) } & \\
\hline $\mathrm{x} \geq 146,25$ & 1 & $1,77 \%$ & Sangat Tinggi \\
$123,75 \leq \mathrm{x}<146,25$ & 18 & $21,18 \%$ & Tinggi \\
$101,25 \leq \mathrm{x}<123,75$ & 49 & $57,65 \%$ & Sedang \\
$78,75 \leq \mathrm{x}<101,25$ & 14 & $16,47 \%$ & Rendah \\
$78,75>\mathrm{x}$ & 3 & $3,53 \%$ & Sangat Rendah \\
\hline Jumlah & 85 & $100 \%$ & \\
\hline Rata-rata & 111,46 & & Sedang \\
\hline
\end{tabular}

Sumber: Data primer setelah diolah (2021)

Berdasarkan table 2 di atas, diperoleh dari 85 siswa kelas VII SMP di kecamatan Burau, $1(1,77 \%)$ siswa yang memiliki kecemasan matematika sangat tinggi, 18 (21,18\%), siswa yang memiliki kecemasan matematika tinggi, $49(57,65 \%)$ siswa yang memiliki kecemasan matematika sedang, $14(16,47 \%)$ siswa yang memiliki kecemasan matematika rendah dan 3 $(3,53 \%)$ siswa yang memiliki kecemasan matematika sangat rendah.

\section{Sikap Siswa Pada Pembelajaran Matematika}

Berdasarkan hasil analisis yang dilakukan, diperoleh gambaran sikap siswa pada pembelajaran matematikasiswa kelas VII SMP di Kecamatan Burau sebagai berikut.

Tabel 3. Hasil uji deskripsi sikap siswa pada pembelajaran matematika siswa kelas VII SMP di kecamatan Burau

\begin{tabular}{lc}
\hline \multicolumn{2}{c}{ Statistics } \\
\hline & Sikap Siswa \\
\hline Jumlah sampel & 85 \\
Rata-rata & 131,92 \\
Median & 133,00 \\
Standar deviasi & 14,93 \\
Variansi & 222,93 \\
Rentang & 68,00 \\
Nilai terendah & 94,00 \\
Nilai tertinggi & 162,00 \\
\hline
\end{tabular}

Sumber: Hasil Analisis Data Primer SPSS (2021)

Berdasarkan Tabel 3 di atas, terlihat bahwa dari 85 siswa, rata-rata sikap siswa pada pembelajaran matematika siswa kelas VII SMP di kecamatan Burau sebesar 131,92, dengan median sebesar 133,00, nilai tertinggi sebesar 162,00, dan nilai terendah sebesar 94,00.

Data sikap siswa pada pembelajaran matematika siswa kelas VII SMP di kecamatan Burau,selanjutnya dikategorisasi menjadi lima kelompok. Berdasarkan pengkategorian tersebut, maka diperoleh distribusi frekuensi sikap siswa pada pembelajaran matematika siswa kelas VII SMP di kecamatan Burau sebagai berikut. 
Tabel 4. Distribusi frekuensi sikap pada pembelajaran matematika siswa kelas VII SMP di kecamatan Burau

\begin{tabular}{cccl}
\hline Interval & Frekuensi & Persentae (\%) & \multicolumn{1}{c}{ Kategori } \\
\hline $\mathrm{x} \geq 149,5$ & 11 & $12,94 \%$ & Sangat Baik \\
$126,5 \leq \mathrm{x}<149,5$ & 42 & $49,41 \%$ & Baik \\
$103,5 \leq \mathrm{x}<126,5$ & 29 & $34,12 \%$ & Cukup Baik \\
$80,5 \leq \mathrm{x}<103,5$ & 3 & $3,53 \%$ & Kurang Baik \\
$80,5>\mathrm{x}$ & 0 & $0,00 \%$ & Tidak Baik \\
\hline Jumlah & 85 & $100 \%$ & \\
\hline Rata-rata & 131,92 & & Baik \\
\hline
\end{tabular}

Sumber: Data primer setelah diolah (2021)

Berdasarkan tabel, dari 85 siswa kelas VII SMP di kecamatan Burau, 11 (12,94\%) siswa yang memiliki sikap sangat baik terhadap pembelajaran matematika, $42(49,41 \%)$ siswa yang memiliki sikap baik terhadap pembelajaran matematika, 29( $34,12 \%)$ siswa yang memiliki sikap cukupbaik terhadap pembelajaran matematika dan 3(3,53\%) siswa yang memiliki sikap cukupbaikterhadap pembelajaran matematika.

\section{Hasil belajar aritmatika sosial siswa}

Berdasarkan hasil analisis yang dilakukan, diperoleh gambaran hasil belajar aritmatika sosial siswa kelas VII SMP di Kecamatan Burau sebagai berikut.

Tabel 5. Hasil uji deskripsi hasil belajar aritmatika sosial siswa siswa kelas VII SMP di kecamatan Burau

\begin{tabular}{lc}
\hline & Statistics \\
\hline Jumlah sampel & Hasil Belajar Aritmatika Sosial \\
Rata-rata & 85 \\
Median & 65,33 \\
Standar deviasi & 66,67 \\
Variansi & 10,84 \\
Rentang & 117,52 \\
Nilai terendah & 50,00 \\
Nilai tertinggi & 40,00 \\
\hline
\end{tabular}

Sumber: Hasil Analisis Data Primer SPSS (2021)

Berdasarkan Tabel 5, terlihat bahwa dari 85 siswa, rata-rata hasil belajar artimatika sosial siswa kelas VII SMP di kecamatan Burau sebesar 65,33, dengan median sebesar 66,67, nilai tertinggi sebesar 90,00, dan nilai terendah sebesar 50,00.

Data hasil belajar aritmatika sosial siswa kelas VII SMP di kecamatan Burau,selanjutnya dikategorisasi menjadi lima kelompok. Berdasarkan pengkategorian tersebut, maka diperoleh distribusi frekuensi hasil belajar aritmatika sosial siswa kelas VII SMP di kecamatan Burau sebagai berikut. 
Tabel 6. Distribusi frekuensi hasil belajar aritmatika sosial siswa kelas VII SMP di kecamatan Burau

\begin{tabular}{lcll}
\hline Interval & $\begin{array}{c}\text { Fre } \\
\text { kuensi }\end{array}$ & $\begin{array}{l}\text { Persentae } \\
(\mathbf{\%})\end{array}$ & Kategori \\
\hline $90 \leq \mathrm{HB} \leq 100$ & 2 & 2,35 & Sangat Tinggi \\
$80 \leq \mathrm{HB}<90$ & 9 & 10,89 & Tinggi \\
$65 \leq \mathrm{x}<80$ & 32 & 37,65 & Sedang \\
$55 \leq \mathrm{x}<65$ & 26 & 30,89 & Rendah \\
$0 \leq \mathrm{HB}<55$ & 16 & 18,82 & Sangat Rendah \\
\hline Jumlah & 85 & 100 & \\
\hline Rata-rata & 65,3 & & Sedang
\end{tabular}

Sumber: Data primer setelah diolah (2021)

Berdasarkan tabel 6, dari 85 siswa kelas VII SMP di kecamatan Burau, 2 (2,35\%) siswa yang memiliki hasil belajar aritmatika sosial sangat tinggi, $9(10,89 \%)$ siswa yang memiliki hasil belajar aritmatika sosial tinggi , $32(37,65 \%)$ siswa yang memiliki hasil belajar aritmatika sosial sedang , 26 siswa yang memiliki hasil belajar aritmatika sosial rendah dengan persentase sebesar 30,89\% dan 16 siswa yang memiliki hasil belajar aritmatika sosial sangat rendah dengan persentase sebesar $18,82 \%$.

\section{Hasil Uji Hipotesis}

Hasil uji normalitas diperoleh nilai probabilitas data kecemasan matematika siswa sebesar $0,74 \geq 0,05$ artinya data kecemasan matematika berdistribusi normal, nilai probabilitas sikap siswa pada pembelajaran matematika sebesar $0,200 \geq 0,05$ artinya data sikap siswa pada pembelajaran matematika berdistribusi normal dan nilai probabilitas hasil belajar aritmatika sosial sebesar $0,200 \geq 0,05$ artinya data hasil belajar aritmatika sosial berdistribusi normal.

Hasil uji linieritas diperoleh sig.deviation from linearity kecemasan siswa terhadap hasil belajar aritmatika sosial sebesar $0,315 \geq 0,05$ artinya ada hubungan yang linier secara signifikan kecemasan siswa dengan hasil belajar aritmatika sosial dan nilai sig.deviation from linearity sikap siswa pada pembelajaran matematika terhadap hasil belajar aritmatika sosial sebesar $0,755 \geq 0,05$.

Hasil analisis uji hipotesis 1, 2, dan 3 diperoleh hasil sebagai berikut.

Tabel 7. Hasil uji hipotesis

\begin{tabular}{llll}
\hline Hipotesis & R Square & Persamaan Regresi & Nilai Probabilitas \\
\hline Hipotesis 1 & 0,089 & $\mathrm{Y}=88,601-0,209 \mathrm{X} 1$ & 0,005 \\
Hipotesis 2 & 0,194 & $\mathrm{Y}=23,179+0,320 \mathrm{X} 2$ & 0,000 \\
Hipotesis 3 & 0,218 & $\mathrm{Y}=41,904-0,101 \mathrm{X} 1+0,262 \mathrm{X} 2$ & 0,000 \\
\hline
\end{tabular}

Sumber: Data Primer setelah diolah (2021)

Berdasarkan table 7 terlihat, nilai probabilitas sebesar $0,005<0,05$, maka $\mathrm{H} 0$ ditolak dan H1 diterima sehingga dapat disimpulkan bahwa terdapat pengaruh kecemasan matematika terhadap hasil belajar aritmatika sosial siswa kelas VII SMP di kecamatan Burau, dengan konstribusi pengaruh sebesar $8,9 \%$. Arah hubungan kecemasan matematika terhadap hasil belajar aritmatika berbanding terbalik. Artinya jika tingkat kecemasan matematika siswa tinggi, maka hasil belajar aritmatika sosial siswa rendah, sebaliknya jika kecemasan matematika rendah, maka hasil belajar aritmatika sosial siswa tinggi. Hal ini sejalan dengan penelitianIksan (2019) yang menyimpulkan bahwa, ada pengaruh negatif antara kecemasan matematis terhadap hasil belajar matematika siswa kelas X IPS 1 diSMA Negeri 1 Cisaat. Pengaruh negatif yang dimaksud adalah jika kecemasan matematis siswa tinggi maka hasil belajar matematika 
siswa rendah begitu sebaliknya jika kecemasan matematis siswa rendah, maka hasil belajar siswa tinggi. lebih lanjut, hasil penelitian Marliani \& Hakim (2015) menemukan bahwa ada perbedaaan hasil belajar matematika siswa yang memiki kecemasan matematika tinggi dan siswa dengan kecemasan matematika rendah. Siswa dengan kecemasan dirirendah, hasil belajar matematikanya lebih tinggi dari siswa dengankecemasan diri tinggi.

Nilai probabilitas hipotesis 2 sebesar $0,000<0,05$ yang berarti $\mathrm{H} 0$ ditolak dan $\mathrm{H} 1$ diterima sehingga dapat disimpulkan terdapat pemgaruh sikap siswa pada pembelajaran matematika terhadap hasil belajar siswa kelas VII SMP di kecamatan Burau dengan konstribusi pengaruh sebesar 19,4\%. Arah hubungan antara sikap siswa pada pembelajaran matematika terhadap hasil belajar aritmatika sosial siswa kelas VII SMP di kecamatan Burau berbanding searah. Artinya semakin baik sikap siswa pada pembelajaran matematika, maka semakin tinggi pula hasil belajar aritmatika sosialnya, begitu pula sebaliknya. Hal ini sejalan dengan penelitian Hartati (2013) yang menemukan bahwa siswa yang memiliki sikap positif pada pelajaran matematika memperoleh hasil belajar matematika lebih tinggi daripada siswa yang memiliki sikap negatif pada pembelajaran matematika lebih lanjut hasil penelitian Purnomo (2016) yang menemukan bahwa terdapat pengaruh positif yang signifikan antara sikap siswa pada pelajaran matematika terhadap prestasi belajar matematika. Dengan kata lain, siswa yang memiliki sikap positif terhadap pelajaran matematika akan dapat mengikuti proses pembelajaran dengan baik, sehingga mampu menghasilkan performa yang terbaik dalam belajarnya terutama pelajaran matematika.

Nilai probabilitas hipotesis 3 sebesar $0,000<0,005$ yang berarti H0 ditolak dan H1 diterima sehingga dapat disimpulkan terdapat pengaruh kecemasan dan sikap siswa pada pembelajaran matematika terhadap hasil belajar siswa kelas VII SMP di kecamatan Burau dengan konstribusi pengaruh sebesar 21,8\%. Arah hubungan antara kecemasan matematika terhadap hasil belajar aritmatika sosial berbanding terbalik dan arah hubungan antara sikap siswa pada pembelajaran matematika terhadap hasil belajar matematika berbanding searah. Artinya jika kecemasan siswa rendah dan sikap siswa pada pembelajaran matematika baik, maka hasil belajar aritmatika sosial siswa akan tinggi.

\section{Kesimpulan}

Berdasarkan hasil penelitian dan pembahasan, kesimpulan dalam penelitian ini adalah 1) Terdapat pengaruh kecemasan matematika terhadap hasil belajar aritmatika sosial sebesar $8,9 \%$. 2) Terdapat pengaruh sikap siswa pada pembelajaran matematika terhadap hasil belajar aritmatika sosial sebesar 19,4\%. 3) Terdapat pengaruh secara bersama-sama kecemasan matematika dan sikap siswa pada pembelajaran matematika terhadap hasil belajar siswa kelas VII SMP di kecamatan Burau sebesar 21,8\%. Dengan demikian dapat disimpulkan bahwa jika kecemasan matematika rendah dan sikap siswa pada pembelajaran matematika baik, maka hasil belajar aritmatika sosial siswa akan tinggi.

\section{DAFTAR PUSTAKA}

Anita, I. W. (2014). Pengaruh kecemasan matematika (mathematics anxiety) terhadap kemampuan koneksi matematis siswa SMP. Infinity Journal, 3(1), 125-132.

Disai, W. I., Dariyo, A., \& Basaria, D. (2018). Hubungan Antara Kecemasan Matematika dan Self-Efficacy Dengan Hasil Belajar Matematika Siswa SMA X Kota Palangka Raya. Jurnal Muara Ilmu Sosial, Humaniora, dan Seni, 1(2), 556-568. 
Ikhsan, M. (2019). Pengaruh Kecemasan Matematis Terhadap Hasil Belajar Matematika. De Fermat: Jurnal Pendidikan Matematika, 2(1), 1-6.

Purnomo, Y. (2016). Pengaruh sikap siswa pada pelajaran matematika dan kemandirian belajar siswa terhadap prestasi belajar matematika. JKPM (Jurnal Kajian Pendidikan Matematika), 2(1), 93-105.

Susilo, T. A. B., \& Agustin, I. (2015). Pengaruh Sikap Siswa pada Matematika terhadap Hasil Belajar Matematika di SMP. Jurnal Pendidikan Matematika, 3(1), 9-16.

Sirajuddin, Arsyad, N, \& Ma'rufi. (2019). Pengaruh Sikap Pada Pelajaran Matematika Terhadap Hasil Belajar Matematika Siswa. Pedagogy: Jurnal Pendidikan Matematika, 4(1), 13-19. 